\title{
Erratum to: "Locked" Scapholunate Instability Diagnosed with 4D Computed Tomography Scan
}

Gregory I. Bain, MBBS, FRACS, PhD ${ }^{1}$ Sathya Vamsi Krishna, MBBS, MS²

Simon MacLean, MBChB, FRCS, PGDipCE ${ }^{3}$ Renee Carr, MBBS ${ }^{1}$ John Slavotinek, MBBS, BSc, FRANZCR ${ }^{4}$

${ }^{1}$ Department of Orthopaedic Surgery, Flinders University, Bedford Park, Adelaide, South Australia, Australia

2 Department of Orthopaedics, St. John's Medical College, Koromangala, Bangalore, India

${ }^{3}$ Tauranga Hospital, Bay Of Plenty District Health Board, Tauranga, New Zealand

${ }^{4}$ Department of Radiology, Flinders University and Flinders Medical Center, Bedford Park, Adelaide, South Australia, Australia

J Wrist Surg 2019;8:e1.
Address for correspondence Gregory I. Bain, MBBS, FRACS, FA(Ortho) A, PhD, Upper Limb and Research, Department of Orthopaedic Surgery, Flinders University and Flinders Medical Center, Bedford Park, Adelaide, South Australia 5042, Australia (e-mail: admin@gregbain.com.au).

\section{ERRATUM}

It has been brought to the publisher's attention that the name of author Simon MacLean was inadvertently missed from the author byline in the above article in the Journal of Wrist Surgery, published online on January 10, 2019 (DOI: 10.1055/s-0038-1675385). The amended author list is as above. 